\title{
Beyond obesity - Thermogenic adipocytes and cardiometabolic health
}

Peter Aldiss ${ }^{1}$, Neele Dellschaft ${ }^{1}$, Harold Sacks ${ }^{3}$, Helen Budge ${ }^{1}$ and Michael E Symonds ${ }^{1}$

${ }^{1}$ The Early Life Research Unit, Division of Child Health, Obstetrics and Gynaecology, and ${ }^{2}$ Nottingham Digestive Disease Centre and Biomedical Research Unit, School of Medicine, University Hospital, University of Nottingham, Nottingham, UK, NG7 2UH

${ }^{3}$ Endocrinology and Diabetes Division, VA Greater Los Angeles Healthcare System, Department of Medicine, University of California, Los Angeles, David Geffen School of Medicine, Los Angeles CA

Disclosure Statement: The authors report no relationships that could be construed as a conflict of interest.

Corresponding author:

Prof Michael E Symonds, Division of Child Health, Obstetrics and Gynaecology, School of Medicine, University Hospital, University of Nottingham, Nottingham, NG7 2UH United Kingdom Telephone:+ 441158230625

Email: michael.symonds@nottingham.ac.uk 


\section{Abstract}

The global prevalence of obesity and related cardiometabolic disease continues to increase through the $21^{\text {st }}$ century. Whilst multi-factorial, obesity is ultimately caused by chronic caloric excess. However, despite numerous interventions focussing on reducing caloric intake these either fail or only elicit short-term changes in body mass. There is now a focus on increasing energy expenditure instead which has stemmed from the recent 're-discovery' of cold-activated brown adipose tissue (BAT) in adult humans and inducible 'beige' adipocytes. Through the unique mitochondrial uncoupling protein (UCP1), these thermogenic adipocytes are capable of combusting large amounts of chemical energy as heat and in animal models can prevent obesity and cardiometabolic disease. At present, human data does not point to a role for thermogenic adipocytes in regulating body weight or fat mass but points to a pivotal role in regulating metabolic health by improving insulin resistance as well as glucose and lipid homeostasis. This review will therefore focus on the metabolic benefits of BAT activation and the mechanisms and signalling pathways by which these could occur including improvements in insulin signalling in peripheral tissues, systemic lipid and cholesterol metabolism and cardiac and vascular function.

Keywords: Brown adipose tissue, Insulin signalling, Glucose metabolism, Lipid metabolism, Cardiometabolic Health.

List of abbreviations: 18F-fluoro-thiaheptadecanoic acid (18FTHA), 2-deoxy-2-[18F]-fluoro-d-glucose (18F-FDG), 2-[1-14C]-deoxyglucose (2-DG), adenosine 3',5'-cyclic monophosphate (cAMP), Adenosine triphosphate (ATP), Adipose Tissue (AT), Adipose triglyceride lipase (ATGL), Angiopoietin-like 4 (ANGPTL4), AMP-activated protein kinase (AMPK), Apolipoprotein E (ApoE), Brown adipose tissue (BAT), Epicardial adipose tissue (EAT), Fibroblast growth factor 21 (FGF21), Free fatty acid (FFA), Glucagon-like peptide 1 (GLP-1), Glucose transporter (GLUT), Guanosine diphosphate (GDP), Hormone sensitive lipase (HSL), Insulin receptor (IR), IR substrates -1 (IRS-1) and -2 (IRS-2), Lipoprotein lipase (LPL), Low-density lipoprotein receptor (Ldlr) Mechanistic target of rapamycin (mTOR), Nicotinamide 
adenine dinucleotide phosphate (NAPDH), Norepinephrine (NE), Perivascular adipose tissue (PVAT), Peroxisome proliferator-activated receptor gamma (PPAR- $\psi$ ), Peroxisome proliferator-activated receptor gamma coactivator 1-alpha (PGC-1 $\alpha$ ), Positron emission tomography-computed tomography (PET-CT) Phosphatidyl-inositol-3, 4, 5-triphosphosphate (PIP3), Phosphoinositide-3-kinase (PI3K), Protein kinase A/B/C (PKA/PKB/PKC), Sirtuin 1 (SIRT1), Triglyceride (TG), Uncoupling protein 1 (UCP1), Very-low-density lipoprotein (vLDL), White adipose tissue (WAT). 


\section{Introduction}

Our current knowledge of adipose tissue physiology has grown exponentially this century and it is now understood that there are at least three types of adipose tissue namely white, brown and beige which differ in their embryological origin, function, molecular characterisation and anatomical distribution (1-3). White adipose tissue (WAT), traditionally viewed as an energy storage vessel is now considered to be potentially the body's largest endocrine organ. In addition to regulating the storage and release of triglycerides in response to changes in energy demand, WAT modulates an array of physiological processes through the secretion of growth factors, cytokines, peptides and adipokines $(4,5)$. Brown adipose tissue (BAT), in contrast, is characterised by the possession of the functionally thermogenic mitochondrial uncoupling protein UCP1. It was traditionally thought to be present primarily in the human neonate where activation at birth acted to defend against hypothermia to the cold extra uterine environment (6). Seminal work had previously demonstrated the presence of brown adipocytes in adult autopsies (7); however, the discovery in 2009 that BAT could be activated pharmacologically and environmentally, was associated inversely with body mass index, with age and metabolic health led to it being heralded as a possible anti-obesity target (8-13). Furthermore, the discovery of inducible 'beige' adipocytes in classical WAT depots which are not only thermogenic in vitro (14) but improve metabolic health in vivo (14-17) has led to further interest on 'browning' white AT.

\section{INSERT FIG 1 HERE}

There is now a wealth of data from animal models suggesting that the activation of thermogenic adipocytes either environmentally or pharmacologically can elicit substantial reductions in adiposity (18). However, these studies are typically done in chronically cold-acclimated rodents exhibiting large and active BAT depots which does not mimic human physiology (19). Moreover, it is also important that the total amount of UCP1 is determined in each depot, and the tissues relative state 
of differentiation/expansion are also measured (20). These factors therefore not only impact on classical brown fat but also beige adipocytes and the elusive search for a stimulus that can provide a greater stimulus than cold to promote UCP1 and the beiging process (20). Evidence in humans certainly suggests that BAT activation increases energy expenditure, however, there is little to suggest a role of thermogenic adipocytes in combating obesity. In fact, long term cold exposure [19C over 1 month] improved glucose homeostasis without an effect on body weight in healthy young men though adiposity was not studied. At present the role of thermogenic adipocytes in humans suggests a potential role in regulating cardiometabolic health in the absence of changes in weight and therefore these cardiometabolic alterations will be the focus of the current review.

\section{Brown adipose tissue, hyperglycemia and insulin resistance}

The dysregulation of insulin signalling and onset of insulin resistance and hyperglycemia is a key feature in obesity and related metabolic syndrome. The mechanisms by which insulin signalling becomes dysregulated is however both complex and tissue specific as the effects of insulin on glucose homeostasis is reliant on numerous downstream intracellular signalling events (21). Typically, the binding of insulin to the $\alpha$-subunit of the insulin receptor (IR) induces the rapid phosphorylation of its $\beta$ subunit and the subsequent activation of tyrosine kinase which in turn allows phosphorylation of IR substrates -1 (IRS-1) and -2 (IRS-2). Phosphorylation of IRS-1 and IRS-2 and subsequent activation of phosphoinositide-3-kinase (PI3K) is key and affects numerous downstream signalling pathways by generating phosphatidyl-inositol-3, 4, 5-triphosphosphate (PIP3), a lipid second messenger. Of these downstream pathways, the Akt/PkB (Protein kinase B) is key and its phosphorylation at the serine 407 and threonine 308 residues is pivotal in driving the metabolic actions of insulin in target tissues.

Importantly, and in the context of this review, recent evidence points to an important role for brown adipocytes in regulating systemic glucose homeostasis with BAT described as a 'glucose sink' (22). It 
is essential therefore to understand the mechanisms by which glucose uptake occurs in thermogenic adipocytes (Figure 2). Glucose uptake in brown adipocytes was described as far back as 1985 (23) and this early in-vivo work in mice demonstrated that the uptake of 2-[1-14C]-deoxyglucose (2-DG) into BAT was

a) greater than in both the brain and heart as well as other peripheral tissues (WAT and skeletal muscle) following insulin administration and

b) greater than in the heart following norepinephrine (NE) administration suggestive that there may be divergent, stimulus specific mechanisms by which glucose uptake occurs.

Insulin stimulated glucose uptake in brown adipocytes is now well understood, occurring by the PI3K-Akt pathway and glucose transporter (GLUT) 4 translocation to the plasma membrane as it does in both WAT and skeletal muscle (24). The mechanisms governing adrenergic stimulation of glucose uptake into brown adipocytes were traditionally less well described. Early in-vitro work demonstrated that glucose uptake in brown adipocytes exposed to NE occurs independently of insulin whilst conversely, insulin mediated glucose uptake into brown adipocytes was dependent on NE concentration (25). It was suggested at the time that the effects of NE were likely to be mediated by adenosine $3^{\prime}, 5^{\prime}$-cyclic monophosphate (CAMP) and we now know that the increased glucose uptake in response to sympathetic activation occurs independently of GLUT4 translocation $(26,27)$. This is largely due to both rapid de novo synthesis of the insulin independent GLUT1 in the plasma membrane by CAMP and also the translocation of GLUT1, promoted by mechanistic target of rapamycin (mTOR) complex $2(26,27)$. Whilst both insulin, and NE-mediated glucose uptake initially occur by different mechanisms adrenergic stimulation ultimately activates the cAMP/protein kinase A (PKA) pathway recruiting PI3K and stimulating multiple protein kinase c's (PKCs). This suggests that NE also acts through similar downstream mechanisms as the classic insulin signalling pathway (28) and it is these mechanisms that underpin the potential for BAT to modulate glucose homeostasis. 
2-deoxy-2-[18F]-fluoro-d-glucose (18F-FDG) was typically used during positron emission tomography (PET)/computed tomography (CT) scans to quantify metabolic activity of tumours in cancer patients. However, since the discovery that 18F-FDG PET-CT can be used to quantify both the presence and activity of BAT its use in healthy populations has increased. In fasted humans undergoing 18F-FDG PET-CT scans cold exposure increases resting energy expenditure, an effect fuelled by oxidation of plasma glucose and free fatty acids (29). Furthermore, cold exposure shifts glucose disposal to active BAT and away from the heart as earlier described $(23,29)$. This increase in glucose utilisation by BAT improves whole body insulin stimulated glucose uptake and insulin sensitivity, changes which are potentially mediated by upregulation of GLUT 1/GLUT 4 or the numerous other genes and enzymes that regulate glucose uptake, glycogen turnover and glycolytic flux as discovered by transcriptomic profiling of sympathetically activated BAT $(28,30)$.

It is these BAT associated changes in glucose homeostasis in humans which have led to the hypothesis that its activation could be a therapeutic target for diabetes.

Long term, intermittent reductions of ambient temperature from $24^{\circ} \mathrm{C}$ to $19^{\circ} \mathrm{C}$ for 10 hours/night for a one month period yield no change in body composition but increase diet induced thermogenesis and post prandial insulin sensitivity in association with reduced leptin and increased adiponectin and GLUT4 expression in subcutaneous AT (31). Short-term cold acclimation over 10 days elicits increases of 18F-FDG uptake into BAT concomitant with a 1.4 fold increase in peripheral insulin sensitivity in type 2 diabetic patients. Given the role of skeletal muscle in regulating glucose homeostasis it is important to note that these effects may be due to the increased translocation of GLUT4 in skeletal muscle which occurred in the absence of changes in insulin signalling and thermogenic genes in WAT $(32,33)$. Even so, it would seem that BAT regulates glucose-induced thermogenesis during an oral glucose tolerance test and that BAT thermogenesis exhibits a diurnal rhythm which is glucose responsive (34). This may be functionally relevant as humans spend a large 
amount of time in the post-prandial state and should be taken into account when considering dietary interventions that are targeted on response of BAT to nutrient excess. Animal studies allude to numerous other benefits of BAT activation. For instance, in models of type 1 diabetes, BAT transplantation can restore euglycaemia independently of insulin through insulin-like growth factor 1 stimulated adipogenesis (35). The formation of healthy WAT and the secretion of hypoglycaemic adipokines are thought to underlie the effects of transplantation on glycaemia, however, the improvements in metabolic homeostasis are reportedly lost in the absence of interleukin-6 (IL6) suggestive that this pleiotropic cytokine has a pivotal role (36). Whilst the mechanisms governing improvements in glucose homeostasis are not completely understood BAT appears to have a major role in regulating glucose metabolism.

It is feasible that the therapeutic activation of thermogenic adipocytes may be a future treatment for diabetes and related endocrine disorders whilst a number of drugs in use clinically or in development may improve insulin sensitivity in part through their effects on brown and beige adipocytes (37).

\section{1) Metformin}

Metformin is a biguanide drug commonly used, alone or in combination with insulin, in the treatment of diabetes. It primarily decreases circulating glucose by inhibiting hepatic gluconeogenesis and by increasing GLUT4-dependent glucose uptake into muscle and WAT through the activation of AMPK and both novel and conventional PKC's (38-40). There is little evidence to date that the improved metabolic homeostasis and modest reductions in body weight occurring with Metformin treatment are due to increased BAT thermogenesis. Indeed, whilst Metformin may increase UCP1 in BAT of lean rats, treatment of both Zucker obese rats and brown adipocytes did not increase BAT UCP1 expression, GDP binding or cellular respiration respectively and importantly no increase in resting energy expenditure is seen in humans (41-45). 
Metformin may have a clearer significance in a perinatal setting where administration during early life may be critical in maintaining BAT function in pups overfed during lactation (46). Despite increased size and adiposity, pups exposed to a caloric surplus during lactation had greater basal UCP1 expression in BAT, likely due to increased PPAR $\alpha$ activation but were less responsive to cold exposure. After weaning to chow mice exhibited greater body mass, adiposity and insulin resistance at 16 weeks of age concomitant with a reduction in BAT UCP1 and the thermogenic response to both cold and a $\beta 3$-agonist. Importantly, when pups were given daily metformin injections throughout lactation the adverse effects on BAT function were reversed at 4 weeks of age despite having similar body weight (46). Long-term effects of this early postnatal life treatment and how this intervention may relate to a clinical situation warrant further research.

\section{2) FGF21}

Fibroblast growth factor (FGF) 21 is an autocrine and endocrine protein secreted primarily from the liver during fasting and starvation, increasing gluconeogenesis and ketogenesis and acting on numerous target tissues including WAT and BAT (47). In addition to having endocrine functions FGF21 can act in an autocrine/paracrine manner. PPAR $\gamma$ induced FGF21 production in WAT does not enter circulation but instead acts on WAT directly activating PPARY from its inactive, sumoylated, form and, with that, enabling stimulation of adipogenesis, GLUT1 expression, glucose uptake and thermogenesis through browning $(48,49)$. FGF21 also acts centrally, activating the sympathetic nervous system whereby subsequent NE production directly stimulates UCP1 expression in both BAT and WAT (50). Additionally, in recent years it has been recognised as a potential 'BATokine' as its expression is increased in BAT following cold exposure though the functional relevance of BAT secreted FGF21 and its contribution to circulating concentrations are not yet understood (51).

Obesity increases expression of FGF21 in liver and WAT as well as circulating FGF21 which may be due to reduced function of its receptor and FGF21 resistance (52-54). Since FGF21 expression is 
controlled by PPAR $\alpha$ and PPARy, stimulation of these transcription factors through antidiabetic drugs like the fibrate class of hypolipidemic drugs and thiazolidinediones, respectively, will induce FGF21 $(55,56)$. Direct administration of FGF21 improves glucose tolerance by decreasing both glucose and insulin concentrations, and lowers body weight, plasma triglycerides and non-esterified fatty acids, in both obese humans and mice, an adaptation partly be mediated by increased non-activity energy expenditure alluding to potential increases in BAT thermogenesis (56-58). Indeed, in mice with dietinduced obesity, FGF21 administration induces UCP1 expression and glucose uptake into brown fat, and also promotes a substantial increase in WAT UCP1 (59-61). Furthermore, cultured brown adipocytes directly stimulated with FGF21 also exhibit an upregulation of UCP1 gene expression together with increased oxygen and glucose consumption (62). Data from UCP1 knockout mice suggests the benefits of FG21 are not entirely due to increased thermogenic activity but also possibly due to reduced energy intake (63). Nevertheless, development and optimisation of recombinant forms of FGF21 to be used in therapy of metabolic diseases such as diabetes are still in progress (56, 64).

3) GLP-1 receptor stimulants

Glucagon-like peptide 1 (GLP-1) is a hormone postprandially released from ileum and colon L-cells. GLP-1 stimulates insulin secretion and inhibits glucagon secretion in a glucose-dependent manner, therefore not leading to hypoglycaemia in addition to slowing gastric emptying thus reducing appetite and body weight $(65,66)$. Endogenous GLP-1 is cleaved by the protease dipeptidyl peptidase 4 (DPP4) within minutes and cleared through the kidney. Synthetic analogues which stimulate the GLP-1 receptor are designed to be resistant to DPP4 degradation and range from short-acting, which are administered twice a day, including liraglutide, to long-acting forms, administered once a week, including albiglutide (67). These analogues are currently in clinical use for the management of hyperglycaemia in type 2 diabetes. In mice it has recently been shown that the metabolic benefits of GLP-1 agonists may occur in part through the activation of BAT and the 
browning of WAT depots $(41,68,69)$. When delivered through intracerebroventricular injection, GLP-1 (68) and its analogue exendin-4 (69) increase BAT thermogenesis via an increased uptake of TG-derived fatty acids and plasma glucose in addition to browning WAT, effects which may occur by activation of hypothalamic AMPK (41). Similar results have been demonstrated when GLP-1 agonists have been administered peripherally (70-72) with the browning of WAT suggested to occur via upregulation of SIRT1 (73). Whilst these effects remain to be confirmed in humans it is feasible that GLP-1 agonists could be suitable candidates to induce browning of visceral adipose tissues.

\section{INSERT FIG 2 HERE}

\section{Thermogenic adipocytes regulate lipid and cholesterol metabolism}

Alterations in systemic lipid and cholesterol metabolism during obesity play a major role in the onset of associated cardiometabolic disease. Insulin and the classical insulin signalling pathways regulate lipid metabolism in both organs and peripheral tissues and dysregulation of insulin signalling effects WAT lipolysis, free fatty acid (FFA) and triglyceride (TG) synthesis and lipid uptake from blood in addition to both hepatic cholesterol synthesis and very-low-density lipoprotein (vLDL) formation (74). Whilst changes in lipid metabolism following BAT activation may relate to improvements in the insulin signalling, BAT utilises lipids as a fuel source stimulating whole body metabolism (Figure 2) (75). During sympathetic stimulation the release of NE from sympathetic nerves results in the activation of adenylyl cyclase and production of cyclic AMP which in turn activates protein kinase A (PKA) . PKA then phosphorylates adipose triglyceride lipase (ATGL) and hormone sensitive lipase (HSL), triggering lipolysis and the release of FFA from intracellular lipid droplets. These FFA enter the mitochondria and activate UCP1 uncoupling oxidative phosphorylation from ATP synthesis to result in the dissipation of heat (76). Ongoing stimulation of BAT requires a replenishment of intracellular lipid, a process mediated by both de novo lipogenesis (77) and the uptake of FA from TG-rich lipoproteins by lipoprotein lipase (LPL) and CD36 (78). Other regulators of lipid mobilisation in BAT 
exist. For example, angiopoietin-like 4 (ANGPTL4), a regulator of LPL activity during both fasting and exercise was recently shown to modulate lipid shuttling in BAT during cold exposure preferentially driving uptake of TG-rich lipoprotein derived FFA, an effect which is regulated by AMP-activated protein kinase (79).

The use of animal models to determine how BAT regulates lipid metabolism has been invaluable. They have been used to demonstrate that activation of BAT, through the above mechanisms can correct hypercholesterolemia and attenuate atherosclerosis $(75,80)$. In contrast, it has also been suggested that BAT activation may be involved in the progression of atherosclerosis due to coldinduced alterations in lipid profile (81). However, it is important to note that the adverse effects of BAT activation are limited to apolipoprotein E K/o (ApoE -/-) and low-density lipoprotein receptor K/o (Ldlr -/-) mice, which both lack a functional ApoE-Ldlr pathway, a requirement for the physiological regulation of lipid metabolism and hepatic clearance of lipoprotein remnants such as LDL and VLDL (80). When exposed to cold the increased metabolic activity of BAT and upregulation of thermogenic genes in WAT of these animals leads to unfavourable changes in total cholesterol, LDLc, intermediate LDL and in particular VLDL in addition to enhanced atherosclerotic lesions and plaque instability (81). This, however, contrasts with the effects of BAT activation seen in APOE*3Leiden.CETP mice. These mice have the human cholesterol ester transfer protein knocked-in and thus have a functional ApoE-Ldlr pathway and 'human-like' lipid metabolism (82). In these animals' administration of the $\beta 3$-adrenergic receptor agonist CL316-243 to activate BAT markedly reduces plasma TG, total cholesterol and VLDL concomitant with increased hepatic clearance of lipoprotein remnants and attenuation of atherosclerosis (80). Whilst common murine models of atherosclerosis closely resemble human pathology their use for studies investigating BAT physiology is limited, in this case the APOE*3-Leiden.CETP mice have a greater translational value and suggest BAT may be a therapeutic target combating CAD in humans (83). 
Relative to glucose metabolism there is less evidence for a role of BAT in human lipid metabolism primarily due to the routine use of FDG tracer uptake in PET-CT studies. Individuals with higher amounts of active BAT, however, exhibit lower fasting TG and higher HDL whilst the expression of LPL and the acetyl-CoA dehydrogenase family of enzymes in UCP-1 containing epicardial adipose tissue is correlated with both circulating TG and HDL $(84,85)$. Using the FFA tracer 18F-fluorothiaheptadecanoic acid (18FTHA) acute cold exposure ( 2 hours) increased both fractional uptake of 18FTHA and uptake of FFA in BAT compared to subcutaneous AT and muscle (86). In BAT positive subjects (based on 18F-FDG disposal) during fasting and acute cold, prolonged cold exposure (5-8h) increases FFA oxidation and contributes to $~ 70 \%$ of the increase in resting energy expenditure. This is likely due to induction of UCP1, together with type 2 deiodenase, $\beta 3$-adrenoreceptor and PGC1 $\alpha$ which have been shown in rodent studies to be essential for BAT thermogenesis (29). BAT activity also correlates with cold-induced lipolysis and whilst glucose uptake is reduced, cold-induced increases in FFA uptake are not impaired in individuals with type 2 diabetes or age matched controls (87). This suggests that cold exposure may be able to modulate lipid metabolism independent of ageing and insulin resistance. More recently BAT activation was shown to correlate with coldinduced changes in whole body FFA oxidation, lipolysis and TG-FFA cycling with BAT demonstrating a 45-fold higher respiration rate (e.g. 45 fold higher capacity for heat generation) compared to WAT (88). Interestingly, whilst cold did not affect plasma TG, cholesterol or lipoproteins reductions in TG and VLDL were seen the following day suggestive that lipid metabolism may be modified after the cessation of cold exposure. These systemic effects are likely to be mediated by cold-induced increases in the expression of genes involved in both thermogenesis and lipid metabolism. Despite the suggested benefits of cold adaptation $(89,90)$, FFA uptake into BAT during acute cold exposure accounts for less than $1 \%$ of total FFA turnover whilst there is no change in circulating TG (86). This points to a minimal role for BAT in the acute regulation of lipid metabolism though increased hepatic VLDL-TAG secretion may confound studies over such a short time-frame (91). It 
has long been speculated since the seminal work of Rothwell and Stock that BAT activation may play a role in diet-induced thermogenesis (92). Whilst there is data to suggest both diet and dietary factors play a role in a compensatory activation of thermogenic tissues, evidence for this in humans is sparse as human BAT studies using PET-CT are typically done in the fasted state (93). Importantly, glucose uptake is impaired following prolonged fasting suggestive that the general fasting state may not be appropriate for assessing the ability of BAT to regulate systemic metabolism (94), although uptake by BAT as measured using PET-CT is much lower than in skeletal muscle after feeding (95). There is now increasing evidence that BAT function is stimulated by feeding

Following 8 weeks of overfeeding in humans there is no increase in BAT thermal activity as measured by taking only two thermal images before feet immersion into cold water, and then two more two minutes later (96). Not surprisingly given the acute nature of this test there was no correlation between thermal activity and metabolic adaptation or body weight (96). It is important to note that instead of using a subscapular reference point, the reference region used includes the background area behind the torso which is cooler than skin temperature and so the results may not be indicative of BAT function. Furthermore, the use of 18FTHA pre and post cold acclimation demonstrates that despite a 2.6-fold increase in BAT oxidative capacity there is no increase in the uptake of dietary fatty acids in the post-prandial state (97). Furthermore, dietary fatty acid uptake by BAT was comparable to abdominal WAT and skeletal muscle and significantly lower than both the heart ( $\sim 55 \%)$ and liver ( $83 \%)$ accounting in total for only $\sim 0.3 \%$ dietary fatty acid uptake. It is important to note here however that the post-prandial cold-exposure period of 240 minutes may not have been sufficient to deplete intracellular lipid in BAT. These stores must normally be depleted before replenishment from circulating lipids can take place with a longer 5-8 hour protocol speculated to be required (88). Methodological differences between the various studies make it difficult to reach a definite conclusion on the potential for BAT to modulate lipid metabolism and in particular this may 
be negligible in short exposure periods. More studies with increased exposure time are needed to determine if the positive effects of BAT activation on lipid metabolism can be replicated (88).

\section{Vascular brown adipocytes and atherosclerosis}

Whilst the main focus in rodents has been on interscapular BAT and 'browning' in recent years there has also been an increased recognition of the physiological relevance of thermogenic adipocytes elsewhere, especially located around the heart (epicardial) and vasculature (perivascular)(98, 99). This is because their contiguity with the myocardium and major vessels respectively implies they might be capable of regulating cardiomyocyte and vascular function in a paracrine and/or endocrine fashion (100). Epicardial AT (EAT) originates from the splanchnic mesoderm and/or the epicardium $(101,102)$ and is primarily located between the myocardium and visceral pericardium where it sits along the myocardium, the atrio- and inter-ventricular grooves and is vascularised by the coronary arteries. EAT provides mechanical protection to the coronary vasculature during contraction (98, 103), modulates coronary vascular tone through the secretion of numerous bioactive peptides (e.g. nitric oxide (104) and angiotensinogen 1-7 (105)) and perhaps protects the myocardium from lipotoxicity through the uptake of intravascular FFA $(106,107)$. Importantly, EAT has also been proposed to protect the myocardium by acting as a source of heat during hypothermia (108) however to date there is no direct evidence to suggest that the UCP1 expressing cells in this depot are thermogenically active. Similar to EAT, perivascular AT (PVAT) is the adipose tissue located around the major vasculature with its main role being to maintain and regulate vascular tone/remodelling and endothelial function/dysfunction $(109,110)$. It is important to note that these tissues are characteristically similar to BAT at birth and also, to some degree throughout adulthood and that the transition from BAT to white-like AT may be due primarily to maternal and early life factors such as under/over-nutrition and diet composition (100, 111, 112). 
With ageing and overnutrition adipocytes accumulate excess lipid, becoming hypertrophic and hypoxic and, after outstripping the vasculature, the hypoxic and inflammatory microenvironment drives the downregulation of mitochondrial function and adrenergic signalling with insulin resistance and atherogenesis ensuing (113-115). It has also been demonstrated in mice that the thermogenic properties of PVAT are essential to optimal cardiovascular health. The complete ablation of PVAT in PDGRF $\alpha$ k/o mice renders animals hypertriglyceridemic (116) suggestinga major role of PVAT in lipid homeostasis. Mice lacking PVAT are also unable to regulate intravascular temperature suggestive that the thermogenic properties of this depot are essential to maintenance of adequate core temperature (116). The role of PVAT in regulating lipid homeostasis is evident in humans where the association between UCP1 expression in human EAT and circulating HDL and triglycerides suggests that this depot plays a role in systemic lipid metabolism (85).

Given the role of dyslipidemia in atherosclerosis the ability for cardiac and vascular adipocytes to regulate intravascular lipid metabolism may be a clinically significant (117). Current evidence also suggests that the brown-to-white transition can modulate redox state (118) with this supported by human data demonstrating excess reactive oxygen species in CAD patients with reduced expression of thermogenic genes (119). Given that components of the mitochondrial electron transport chain in PVAT are critical regulators of vascular tone it would suggest that the adipocytes present in EAT and PVAT may modulate vascular and myocardial redox state (112) and that 'whitening' of these may drive disease partly through excess reactive oxygen species. In fact, BAT regulates vascular function through production of the anti-contractile factor hydrogen peroxide which is regulated by NADPH Oxidase 4 and alters vascular contractility through activation of protein-kinase G1 $\alpha$ (120). Importantly, mechanisms regulating contractiliy differ in mesenteric PVAT (which resembles WAT) and browning this depot increases the anti-contractile effect through hydrogen peroxide dependant mechanisms in a manner similar to BAT. Thus, the anti-contractile effects of brown adipose tissue may be lost in the transition to WAT that occurs with ageing and obesity but may be restored in the 
presence of browning. Whilst manipulating the phenotype of adipocytes local to the vasculature is clinically challenging they offer a novel target to alleviate obesity associated vascular disease and it is clear that cross-talk between these adipocytes, the myocardium and vascular wall are of great importance

\section{Conclusion and Outlook}

It is clear that activating BAT is an attractive target for the prevention of metabolic and cardiovascular disease. To date there is clear evidence that BAT can improve glucose and insulin homeostasis through insulin-dependent and independent mechanisms (90). Furthermore, BAT activation may be a means of manipulating systemic lipid metabolism in humans but will require further work to validate the promising results shown in rodents $(80,88)$. Future work will no doubt further target the manipulation of thermogenic adipocytes by pharmacological and environmental means whilst the development of new tracers and imaging methods will greatly enhance our understanding of both BAT and 'beige' adipocyte biology.

\section{Highlights}

- Rodent data provides clear evidence of a role for BAT in reducing adiposity.

- To date no human study has shown that activating BAT leads to reductions in adiposity.

- Active brown adipose tissue plays a key role in glucose and insulin homeostasis in humans.

- Activation of BAT may play a key role in human triglyceride metabolism but further studies are needed.

- Brown adipocytes surrounding the heart and vasculature may play a key role in attenuating atherosclerosis.

\section{Acknowledgements}

P. Aldiss is funded by the British Heart Foundation (Grant number - FS/15/4/31184) 


\section{References}

1. Cinti S. The adipose organ at a glance. Dis Model Mech. 2012;5(5):588-94.

2. Sanchez-Gurmaches J, Guertin DA. Adipocyte lineages: tracing back the origins of fat. Biochim Biophys Acta. 2014;1842(3):340-51.

3. de Jong JM, Larsson O, Cannon B, Nedergaard J. A stringent validation of mouse adipose tissue identity markers. Am J Physiol Endocrinol Metab. 2015;308(12):E1085-105.

4. Grant RW, Dixit VD. Adipose tissue as an immunological organ. Obesity (Silver Spring). 2015;23(3):512-8.

5. Kershaw EE, Flier JS. Adipose tissue as an endocrine organ. J Clin Endocrinol Metab. 2004;89(6):2548-56.

6. Symonds ME, Pope M, Budge H. The Ontogeny of Brown Adipose Tissue. Annu Rev Nutr. 2015;35:295-320.

7. Heaton JM. The distribution of brown adipose tissue in the human. J Anat. 1972;112(Pt 1):35-

9.

8. Cypess AM, White AP, Vernochet C, Schulz TJ, Xue R, Sass CA, Huang TL, Roberts-Toler C, Weiner LS, Sze C, Chacko AT, Deschamps LN, Herder LM, Truchan N, Glasgow AL, Holman AR, Gavrila A, Hasselgren PO, Mori MA, Molla M, Tseng YH. Anatomical localization, gene expression profiling and functional characterization of adult human neck brown fat. Nat Med. 2013;19(5):635-9.

9. Cypess AM, Lehman S, Williams G, Tal I, Rodman D, Goldfine AB, Kuo FC, Palmer EL, Tseng YH, Doria A, Kolodny GM, Kahn CR. Identification and importance of brown adipose tissue in adult humans. N Engl J Med. 2009;360(15):1509-17.

10. Robinson L, Ojha S, Symonds ME, Budge H. Body mass index as a determinant of brown adipose tissue function in healthy children. J Pediatr. 2014;164(2):318-22 e1.

11. Symonds ME, Henderson K, Elvidge L, Bosman C, Sharkey D, Perkins AC, Budge H. Thermal imaging to assess age-related changes of skin temperature within the supraclavicular region colocating with brown adipose tissue in healthy children. J Pediatr. 2012;161(5):892-8.

12. Ouellet V, Routhier-Labadie A, Bellemare W, Lakhal-Chaieb L, Turcotte E, Carpentier AC, Richard D. Outdoor temperature, age, sex, body mass index, and diabetic status determine the prevalence, mass, and glucose-uptake activity of 18F-FDG-detected BAT in humans. J Clin Endocrinol Metab. 2011;96(1):192-9.

13. Yoneshiro $T$, Aita $S$, Matsushita $M$, Okamatsu-Ogura $Y$, Kameya $T$, Kawai $Y$, Miyagawa $M$, Tsujisaki M, Saito M. Age-related decrease in cold-activated brown adipose tissue and accumulation of body fat in healthy humans. Obesity (Silver Spring). 2011;19(9):1755-60.

14. Wu J, Bostrom P, Sparks LM, Ye L, Choi JH, Giang AH, Khandekar M, Virtanen KA, Nuutila P, Schaart G, Huang K, Tu H, van Marken Lichtenbelt WD, Hoeks J, Enerback S, Schrauwen P, Spiegelman BM. Beige adipocytes are a distinct type of thermogenic fat cell in mouse and human. Cell. 2012;150(2):366-76.

15. De Matteis R, Lucertini F, Guescini M, Polidori E, Zeppa S, Stocchi V, Cinti S, Cuppini R. Exercise as a new physiological stimulus for brown adipose tissue activity. Nutr Metab Cardiovasc Dis. 2013;23(6):582-90.

16. Sidossis LS, Porter C, Saraf MK, Borsheim E, Radhakrishnan RS, Chao T, Ali A, Chondronikola M, Mlcak R, Finnerty CC, Hawkins HK, Toliver-Kinsky T, Herndon DN. Browning of Subcutaneous White Adipose Tissue in Humans after Severe Adrenergic Stress. Cell Metab. 2015;22(2):219-27.

17. Shabalina IG, Petrovic N, de Jong JM, Kalinovich AV, Cannon B, Nedergaard J. UCP1 in brite/beige adipose tissue mitochondria is functionally thermogenic. Cell Rep. 2013;5(5):1196-203.

18. Poekes L, Lanthier N, Leclercq IA. Brown adipose tissue: a potential target in the fight against obesity and the metabolic syndrome. Clin Sci (Lond). 2015;129(11):933-49.

19. Maloney SK, Fuller A, Mitchell D, Gordon C, Overton JM. Translating animal model research: does it matter that our rodents are cold? Physiology (Bethesda). 2014;29(6):413-20.

20. Kalinovich AV, de Jong JM, Cannon B, Nedergaard J. UCP1 in adipose tissues: two steps to full browning. Biochimie. 2017;134:127-37. 
21. Cantley J. The control of insulin secretion by adipokines: current evidence for adipocyte-beta cell endocrine signalling in metabolic homeostasis. Mamm Genome. 2014;25(9-10):442-54.

22. Villarroya F, Vidal-Puig A. Beyond the sympathetic tone: the new brown fat activators. Cell Metab. 2013;17(5):638-43.

23. Cooney GJ, Caterson ID, Newsholme EA. The effect of insulin and noradrenaline on the uptake of 2-[1-14C]deoxyglucose in vivo by brown adipose tissue and other glucose-utilising tissues of the mouse. FEBS Lett. 1985;188(2):257-61.

24. Zaid H, Antonescu CN, Randhawa VK, Klip A. Insulin action on glucose transporters through molecular switches, tracks and tethers. Biochem J. 2008;413(2):201-15.

25. Marette A, Bukowiecki LJ. Stimulation of glucose transport by insulin and norepinephrine in isolated rat brown adipocytes. Am J Physiol. 1989;257(4 Pt 1):C714-21.

26. Dallner OS, Chernogubova E, Brolinson KA, Bengtsson T. Beta3-adrenergic receptors stimulate glucose uptake in brown adipocytes by two mechanisms independently of glucose transporter 4 translocation. Endocrinology. 2006;147(12):5730-9.

27. Olsen JM, Sato M, Dallner OS, Sandstrom AL, Pisani DF, Chambard JC, Amri EZ, Hutchinson DS, Bengtsson T. Glucose uptake in brown fat cells is dependent on mTOR complex 2-promoted GLUT1 translocation. J Cell Biol. 2014;207(3):365-74.

28. Chernogubova E, Cannon B, Bengtsson T. Norepinephrine increases glucose transport in brown adipocytes via beta3-adrenoceptors through a cAMP, PKA, and PI3-kinase-dependent pathway stimulating conventional and novel PKCs. Endocrinology. 2004;145(1):269-80.

29. Chondronikola M, Volpi E, Borsheim E, Porter C, Annamalai P, Enerback S, Lidell ME, Saraf MK, Labbe SM, Hurren NM, Yfanti C, Chao T, Andersen CR, Cesani F, Hawkins H, Sidossis LS. Brown adipose tissue improves whole-body glucose homeostasis and insulin sensitivity in humans. Diabetes. 2014;63(12):4089-99.

30. Hao Q, Yadav R, Basse AL, Petersen S, Sonne SB, Rasmussen S, Zhu Q, Lu Z, Wang J, Audouze K, Gupta R, Madsen L, Kristiansen K, Hansen JB. Transcriptome profiling of brown adipose tissue during cold exposure reveals extensive regulation of glucose metabolism. Am J Physiol Endocrinol Metab. 2015;308(5):E380-92.

31. Lee P, Smith S, Linderman J, Courville AB, Brychta RJ, Dieckmann W, Werner CD, Chen KY, Celi FS. Temperature-acclimated brown adipose tissue modulates insulin sensitivity in humans. Diabetes. 2014;63(11):3686-98.

32. Blondin DP, Labbe SM, Phoenix S, Guerin B, Turcotte EE, Richard D, Carpentier AC, Haman F. Contributions of white and brown adipose tissues and skeletal muscles to acute cold-induced metabolic responses in healthy men. J Physiol. 2015;593(3):701-14.

33. Hanssen MJ, Hoeks J, Brans B, van der Lans AA, Schaart G, van den Driessche JJ, Jorgensen JA, Boekschoten MV, Hesselink MK, Havekes B, Kersten S, Mottaghy FM, van Marken Lichtenbelt WD, Schrauwen P. Short-term cold acclimation improves insulin sensitivity in patients with type 2 diabetes mellitus. Nat Med. 2015;21(8):863-5.

34. Lee P, Bova R, Schofield L, Bryant W, Dieckmann W, Slattery A, Govendir MA, Emmett L, Greenfield JR. Brown Adipose Tissue Exhibits a Glucose-Responsive Thermogenic Biorhythm in Humans. Cell Metab. 2016;23(4):602-9.

35. Gunawardana SC, Piston DW. Insulin-independent reversal of type 1 diabetes in nonobese diabetic mice with brown adipose tissue transplant. Am J Physiol Endocrinol Metab. 2015;308(12):E1043-55.

36. Stanford KI, Middelbeek RJ, Townsend KL, An D, Nygaard EB, Hitchcox KM, Markan KR, Nakano $\mathrm{K}$, Hirshman MF, Tseng YH, Goodyear LJ. Brown adipose tissue regulates glucose homeostasis and insulin sensitivity. J Clin Invest. 2013;123(1):215-23.

37. Yuan X, Hu T, Zhao H, Huang Y, Ye R, Lin J, Zhang C, Zhang H, Wei G, Zhou H, Dong M, Zhao J, Wang $\mathrm{H}$, Liu $\mathrm{Q}$, Lee $\mathrm{HJ}$, Jin $\mathrm{W}$, Chen ZJ. Brown adipose tissue transplantation ameliorates polycystic ovary syndrome. Proc Natl Acad Sci U S A. 2016;113(10):2708-13. 
38. Turban S, Stretton C, Drouin O, Green CJ, Watson ML, Gray A, Ross F, Lantier L, Viollet B, Hardie DG, Marette A, Hundal HS. Defining the contribution of AMP-activated protein kinase (AMPK) and protein kinase $C(P K C)$ in regulation of glucose uptake by metformin in skeletal muscle cells. J Biol Chem. 2012;287(24):20088-99.

39. Zhou G, Myers R, Li Y, Chen Y, Shen X, Fenyk-Melody J, Wu M, Ventre J, Doebber T, Fujii N, Musi N, Hirshman MF, Goodyear LJ, Moller DE. Role of AMP-activated protein kinase in mechanism of metformin action. J Clin Invest. 2001;108(8):1167-74.

40. Hundal RS, Krssak M, Dufour S, Laurent D, Lebon V, Chandramouli V, Inzucchi SE, Schumann WC, Petersen KF, Landau BR, Shulman GI. Mechanism by which metformin reduces glucose production in type 2 diabetes. Diabetes. 2000;49(12):2063-9.

41. Beiroa D, Imbernon M, Gallego R, Senra A, Herranz D, Villarroya F, Serrano M, Ferno J, Salvador J, Escalada J, Dieguez C, Lopez M, Fruhbeck G, Nogueiras R. GLP-1 agonism stimulates brown adipose tissue thermogenesis and browning through hypothalamic AMPK. Diabetes. 2014;63(10):3346-58.

42. Tokubuchi I, Tajiri Y, Iwata S, Hara K, Wada N, Hashinaga T, Nakayama H, Mifune H, Yamada $K$. Beneficial effects of metformin on energy metabolism and visceral fat volume through a possible mechanism of fatty acid oxidation in human subjects and rats. PLoS One. 2017;12(2):e0171293.

43. Keates AC, Bailey CJ. Metformin does not increase energy expenditure of brown fat. Biochem Pharmacol. 1993;45(4):971-3.

44. Rouru J, Isaksson K, Santti E, Huupponen R, Koulu M. Metformin and brown adipose tissue thermogenetic activity in genetically obese Zucker rats. Eur J Pharmacol. 1993;246(1):67-71.

45. Savontaus E, Rouru J, Boss O, Huupponen R, Koulu M. Differential regulation of uncoupling proteins by chronic treatments with beta 3-adrenergic agonist BRL 35135 and metformin in obese fa/fa Zucker rats. Biochem Biophys Res Commun. 1998;246(3):899-904.

46. Liang X, Yang Q, Zhang L, Maricelli JW, Rodgers BD, Zhu MJ, Du M. Maternal high-fat diet during lactation impairs thermogenic function of brown adipose tissue in offspring mice. Sci Rep. 2016;6:34345.

47. Giralt M, Gavalda-Navarro A, Villarroya F. Fibroblast growth factor-21, energy balance and obesity. Mol Cell Endocrinol. 2015;418 Pt 1:66-73.

48. Dutchak PA, Katafuchi T, Bookout AL, Choi JH, Yu RT, Mangelsdorf DJ, Kliewer SA. Fibroblast growth factor-21 regulates PPARgamma activity and the antidiabetic actions of thiazolidinediones. Cell. 2012;148(3):556-67.

49. Moyers JS, Shiyanova TL, Mehrbod F, Dunbar JD, Noblitt TW, Otto KA, Reifel-Miller A, Kharitonenkov A. Molecular determinants of FGF-21 activity-synergy and cross-talk with PPARgamma signaling. J Cell Physiol. 2007;210(1):1-6.

50. Douris N, Stevanovic DM, Fisher FM, Cisu TI, Chee MJ, Nguyen NL, Zarebidaki E, Adams AC, Kharitonenkov A, Flier JS, Bartness TJ, Maratos-Flier E. Central Fibroblast Growth Factor 21 Browns White Fat via Sympathetic Action in Male Mice. Endocrinology. 2015;156(7):2470-81.

51. Hondares E, Iglesias R, Giralt A, Gonzalez FJ, Giralt M, Mampel T, Villarroya F. Thermogenic activation induces FGF21 expression and release in brown adipose tissue. J Biol Chem. 2011;286(15):12983-90.

52. Tan BK, Hallschmid M, Adya R, Kern W, Lehnert H, Randeva HS. Fibroblast growth factor 21 (FGF21) in human cerebrospinal fluid: relationship with plasma FGF21 and body adiposity. Diabetes. 2011;60(11):2758-62.

53. Fisher FM, Chui PC, Antonellis PJ, Bina HA, Kharitonenkov A, Flier JS, Maratos-Flier E. Obesity is a fibroblast growth factor 21 (FGF21)-resistant state. Diabetes. 2010;59(11):2781-9.

54. Hale C, Chen MM, Stanislaus S, Chinookoswong N, Hager T, Wang M, Veniant MM, Xu J. Lack of overt FGF21 resistance in two mouse models of obesity and insulin resistance. Endocrinology. 2012;153(1):69-80.

55. Badman MK, Pissios P, Kennedy AR, Koukos G, Flier JS, Maratos-Flier E. Hepatic fibroblast growth factor 21 is regulated by PPARalpha and is a key mediator of hepatic lipid metabolism in ketotic states. Cell Metab. 2007;5(6):426-37. 
56. Gaich G, Chien JY, Fu H, Glass LC, Deeg MA, Holland WL, Kharitonenkov A, Bumol T, Schilske HK, Moller DE. The effects of LY2405319, an FGF21 analog, in obese human subjects with type 2 diabetes. Cell Metab. 2013;18(3):333-40.

57. Kharitonenkov A, Shanafelt AB. FGF21: a novel prospect for the treatment of metabolic diseases. Curr Opin Investig Drugs. 2009;10(4):359-64.

58. Xu J, Lloyd DJ, Hale C, Stanislaus S, Chen M, Sivits G, Vonderfecht S, Hecht R, Li YS, Lindberg RA, Chen JL, Jung DY, Zhang Z, Ko HJ, Kim JK, Veniant MM. Fibroblast growth factor 21 reverses hepatic steatosis, increases energy expenditure, and improves insulin sensitivity in diet-induced obese mice. Diabetes. 2009;58(1):250-9.

59. Bernardo B, Lu M, Bandyopadhyay G, Li P, Zhou Y, Huang J, Levin N, Tomas EM, Calle RA, Erion DM, Rolph TP, Brenner M, Talukdar S. FGF21 does not require interscapular brown adipose tissue and improves liver metabolic profile in animal models of obesity and insulin-resistance. Sci Rep. 2015;5:11382.

60. Coskun T, Bina HA, Schneider MA, Dunbar JD, Hu CC, Chen Y, Moller DE, Kharitonenkov A. Fibroblast growth factor 21 corrects obesity in mice. Endocrinology. 2008;149(12):6018-27.

61. Camporez JP, Jornayvaz FR, Petersen MC, Pesta D, Guigni BA, Serr J, Zhang D, Kahn M, Samuel VT, Jurczak MJ, Shulman GI. Cellular mechanisms by which FGF21 improves insulin sensitivity in male mice. Endocrinology. 2013;154(9):3099-109.

62. Hondares E, Rosell M, Gonzalez FJ, Giralt M, Iglesias R, Villarroya F. Hepatic FGF21 expression is induced at birth via PPARalpha in response to milk intake and contributes to thermogenic activation of neonatal brown fat. Cell Metab. 2010;11(3):206-12.

63. Samms RJ, Smith DP, Cheng CC, Antonellis PP, Perfield JW, 2nd, Kharitonenkov A, Gimeno RE, Adams AC. Discrete Aspects of FGF21 In Vivo Pharmacology Do Not Require UCP1. Cell Rep. 2015;11(7):991-9.

64. Dong JQ, Rossulek M, Somayaji VR, Baltrukonis D, Liang Y, Hudson K, Hernandez-Illas M, Calle RA. Pharmacokinetics and pharmacodynamics of PF-05231023, a novel long-acting FGF21 mimetic, in a first-in-human study. Br J Clin Pharmacol. 2015;80(5):1051-63.

65. Dockray GJ. Enteroendocrine cell signalling via the vagus nerve. Curr Opin Pharmacol. 2013;13(6):954-8.

66. Sisley S, Gutierrez-Aguilar R, Scott M, D'Alessio DA, Sandoval DA, Seeley RJ. Neuronal GLP1R mediates liraglutide's anorectic but not glucose-lowering effect. J Clin Invest. 2014;124(6):2456-63.

67. Matthews JE, Stewart MW, De Boever EH, Dobbins RL, Hodge RJ, Walker SE, Holland MC, Bush MA, Albiglutide Study G. Pharmacodynamics, pharmacokinetics, safety, and tolerability of albiglutide, a long-acting glucagon-like peptide-1 mimetic, in patients with type 2 diabetes. J Clin Endocrinol Metab. 2008;93(12):4810-7.

68. Lockie SH, Heppner KM, Chaudhary N, Chabenne JR, Morgan DA, Veyrat-Durebex C, Ananthakrishnan G, Rohner-Jeanrenaud F, Drucker DJ, DiMarchi R, Rahmouni K, Oldfield BJ, Tschop $\mathrm{MH}$, Perez-Tilve $\mathrm{D}$. Direct control of brown adipose tissue thermogenesis by central nervous system glucagon-like peptide-1 receptor signaling. Diabetes. 2012;61(11):2753-62.

69. Kooijman S, Wang Y, Parlevliet ET, Boon MR, Edelschaap D, Snaterse G, Pijl H, Romijn JA, Rensen PC. Central GLP-1 receptor signalling accelerates plasma clearance of triacylglycerol and glucose by activating brown adipose tissue in mice. Diabetologia. 2015;58(11):2637-46.

70. Heppner KM, Marks S, Holland J, Ottaway N, Smiley D, Dimarchi R, Perez-Tilve D. Contribution of brown adipose tissue activity to the control of energy balance by GLP-1 receptor signalling in mice. Diabetologia. 2015;58(9):2124-32.

71. Tomas E, Stanojevic V, McManus K, Khatri A, Everill P, Bachovchin WW, Habener JF. GLP-1(3236)amide Pentapeptide Increases Basal Energy Expenditure and Inhibits Weight Gain in Obese Mice. Diabetes. 2015;64(7):2409-19.

72. Wei Q, Li L, Chen JA, Wang SH, Sun ZL. Exendin-4 improves thermogenic capacity by regulating fat metabolism on brown adipose tissue in mice with diet-induced obesity. Ann Clin Lab Sci. 2015;45(2):158-65. 
73. Xu F, Lin B, Zheng X, Chen Z, Cao H, Xu H, Liang H, Weng J. GLP-1 receptor agonist promotes brown remodelling in mouse white adipose tissue through SIRT1. Diabetologia. 2016;59(5):1059-69.

74. Dimitriadis G, Mitrou P, Lambadiari V, Maratou E, Raptis SA. Insulin effects in muscle and adipose tissue. Diabetes Res Clin Pract. 2011;93 Suppl 1:S52-9.

75. Bartelt A, Bruns OT, Reimer R, Hohenberg H, Ittrich H, Peldschus K, Kaul MG, Tromsdorf UI, Weller H, Waurisch C, Eychmuller A, Gordts PL, Rinninger F, Bruegelmann K, Freund B, Nielsen P, Merkel $M$, Heeren J. Brown adipose tissue activity controls triglyceride clearance. Nat Med. 2011;17(2):200-5.

76. Cannon B, Nedergaard J. Brown adipose tissue: function and physiological significance. Physiol Rev. 2004;84(1):277-359.

77. Mottillo EP, Balasubramanian P, Lee YH, Weng C, Kershaw EE, Granneman JG. Coupling of lipolysis and de novo lipogenesis in brown, beige, and white adipose tissues during chronic beta3adrenergic receptor activation. J Lipid Res. 2014;55(11):2276-86.

78. Laplante M, Festuccia WT, Soucy G, Blanchard PG, Renaud A, Berger JP, Olivecrona G, Deshaies Y. Tissue-specific postprandial clearance is the major determinant of PPARgamma-induced triglyceride lowering in the rat. Am J Physiol Regul Integr Comp Physiol. 2009;296(1):R57-66.

79. Dijk W, Heine M, Vergnes L, Boon MR, Schaart G, Hesselink MK, Reue K, van Marken Lichtenbelt WD, Olivecrona G, Rensen PC, Heeren J, Kersten S. ANGPTL4 mediates shuttling of lipid fuel to brown adipose tissue during sustained cold exposure. Elife. 2015;4.

80. Berbee JF, Boon MR, Khedoe PP, Bartelt A, Schlein C, Worthmann A, Kooijman S, Hoeke G, Mol IM, John C, Jung C, Vazirpanah N, Brouwers LP, Gordts PL, Esko JD, Hiemstra PS, Havekes LM, Scheja L, Heeren J, Rensen PC. Brown fat activation reduces hypercholesterolaemia and protects from atherosclerosis development. Nat Commun. 2015;6:6356.

81. Dong M, Yang X, Lim S, Cao Z, Honek J, Lu H, Zhang C, Seki T, Hosaka K, Wahlberg E, Yang J, Zhang L, Lanne T, Sun B, Li X, Liu Y, Zhang Y, Cao Y. Cold exposure promotes atherosclerotic plaque growth and instability via UCP1-dependent lipolysis. Cell Metab. 2013;18(1):118-29.

82. Zadelaar S, Kleemann R, Verschuren L, de Vries-Van der Weij J, van der Hoorn J, Princen HM, Kooistra T. Mouse models for atherosclerosis and pharmaceutical modifiers. Arterioscler Thromb Vasc Biol. 2007;27(8):1706-21.

83. von Scheidt M, Zhao Y, Kurt Z, Pan C, Zeng L, Yang X, Schunkert H, Lusis AJ. Applications and Limitations of Mouse Models for Understanding Human Atherosclerosis. Cell Metab. 2017;25(2):24861.

84. Wang $Q$, Zhang $M, X u M, G u$ W, Xi Y, Qi L, Li B, Wang W. Brown adipose tissue activation is inversely related to central obesity and metabolic parameters in adult human. PLoS One. 2015;10(4):e0123795.

85. Chechi K, Blanchard PG, Mathieu P, Deshaies Y, Richard D. Brown fat like gene expression in the epicardial fat depot correlates with circulating HDL-cholesterol and triglycerides in patients with coronary artery disease. Int J Cardiol. 2013;167(5):2264-70.

86. Ouellet V, Labbe SM, Blondin DP, Phoenix S, Guerin B, Haman F, Turcotte EE, Richard D, Carpentier AC. Brown adipose tissue oxidative metabolism contributes to energy expenditure during acute cold exposure in humans. J Clin Invest. 2012;122(2):545-52.

87. Blondin DP, Labbe SM, Noll C, Kunach M, Phoenix S, Guerin B, Turcotte EE, Haman F, Richard D, Carpentier AC. Selective Impairment of Glucose but Not Fatty Acid or Oxidative Metabolism in Brown Adipose Tissue of Subjects With Type 2 Diabetes. Diabetes. 2015;64(7):2388-97.

88. Chondronikola M, Volpi E, Borsheim E, Porter C, Saraf MK, Annamalai P, Yfanti C, Chao T, Wong D, Shinoda K, Labbe SM, Hurren NM, Cesani F, Kajimura S, Sidossis LS. Brown Adipose Tissue Activation Is Linked to Distinct Systemic Effects on Lipid Metabolism in Humans. Cell Metab. 2016;23(6):1200-6. 89. Johnson F, Mavrogianni A, Ucci M, Vidal-Puig A, Wardle J. Could increased time spent in a thermal comfort zone contribute to population increases in obesity? Obes Rev. 2011;12(7):543-51.

90. Betz MJ, Enerback S. Human Brown Adipose Tissue: What We Have Learned So Far. Diabetes. 2015;64(7):2352-60. 
91. Hoeke G, Kooijman S, Boon MR, Rensen PC, Berbee JF. Role of Brown Fat in Lipoprotein Metabolism and Atherosclerosis. Circ Res. 2016;118(1):173-82.

92. Rothwell NJ, Stock MJ. Luxuskonsumption, diet-induced thermogenesis and brown fat: the case in favour. Clin Sci (Lond). 1983;64(1):19-23.

93. Fromme T, Klingenspor M. Uncoupling protein 1 expression and high-fat diets. Am J Physiol Regul Integr Comp Physiol. 2011;300(1):R1-8.

94. Hanssen MJ, Wierts R, Hoeks J, Gemmink A, Brans B, Mottaghy FM, Schrauwen P, van Marken Lichtenbelt WD. Glucose uptake in human brown adipose tissue is impaired upon fasting-induced insulin resistance. Diabetologia. 2015;58(3):586-95.

95. Vosselman MJ, Brans B, van der Lans AA, Wierts R, van Baak MA, Mottaghy FM, Schrauwen P, van Marken Lichtenbelt WD. Brown adipose tissue activity after a high-calorie meal in humans. Am J Clin Nutr. 2013;98(1):57-64.

96. Peterson CM, Orooji M, Johnson DN, Naraghi-Pour M, Ravussin E. Brown adipose tissue does not seem to mediate metabolic adaptation to overfeeding in men. Obesity (Silver Spring). 2017.

97. Blondin DP, Tingelstad HC, Noll C, Frisch F, Phoenix S, Guerin B, Turcotte EE, Richard D, Haman F, Carpentier AC. Dietary fatty acid metabolism of brown adipose tissue in cold-acclimated men. Nat Commun. 2017;8:14146.

98. lacobellis G. Local and systemic effects of the multifaceted epicardial adipose tissue depot. Nat Rev Endocrinol. 2015;11(6):363-71.

99. Gil-Ortega M, Somoza B, Huang Y, Gollasch M, Fernandez-Alfonso MS. Regional differences in perivascular adipose tissue impacting vascular homeostasis. Trends Endocrinol Metab. 2015;26(7):367-75.

100. Aldiss P, Davies G, Woods R, Budge H, Sacks HS, Symonds ME. 'Browning' the cardiac and perivascular adipose tissues to modulate cardiovascular risk. Int J Cardiol. 2017;228:265-74.

101. Yamaguchi Y, Cavallero S, Patterson M, Shen H, Xu J, Kumar SR, Sucov HM. Adipogenesis and epicardial adipose tissue: a novel fate of the epicardium induced by mesenchymal transformation and PPARgamma activation. Proc Natl Acad Sci U S A. 2015;112(7):2070-5.

102. Sacks HS, Fain JN. Human epicardial adipose tissue: a review. Am Heart J. 2007;153(6):907-17. 103. Szasz T, Webb RC. Perivascular adipose tissue: more than just structural support. Clin Sci (Lond). 2012;122(1):1-12.

104. Gao YJ, Lu C, Su LY, Sharma AM, Lee RM. Modulation of vascular function by perivascular adipose tissue: the role of endothelium and hydrogen peroxide. Br J Pharmacol. 2007;151(3):323-31.

105. Lee RM, Lu C, Su LY, Gao YJ. Endothelium-dependent relaxation factor released by perivascular adipose tissue. J Hypertens. 2009;27(4):782-90.

106. Marchington JM, Mattacks CA, Pond CM. Adipose tissue in the mammalian heart and pericardium: structure, foetal development and biochemical properties. Comp Biochem Physiol B. 1989;94(2):225-32.

107. Marchington JM, Pond CM. Site-specific properties of pericardial and epicardial adipose tissue: the effects of insulin and high-fat feeding on lipogenesis and the incorporation of fatty acids in vitro. Int J Obes. 1990;14(12):1013-22.

108. Sacks HS, Fain JN, Holman B, Cheema P, Chary A, Parks F, Karas J, Optican R, Bahouth SW, Garrett E, Wolf RY, Carter RA, Robbins T, Wolford D, Samaha J. Uncoupling protein-1 and related messenger ribonucleic acids in human epicardial and other adipose tissues: epicardial fat functioning as brown fat. J Clin Endocrinol Metab. 2009;94(9):3611-5.

109. Szasz T, Bomfim GF, Webb RC. The influence of perivascular adipose tissue on vascular homeostasis. Vasc Health Risk Manag. 2013;9:105-16.

110. Ozen G, Daci A, Norel X, Topal G. Human perivascular adipose tissue dysfunction as a cause of vascular disease: Focus on vascular tone and wall remodeling. Eur J Pharmacol. 2015;766:16-24.

111. Ojha S, Fainberg HP, Wilson V, Pelella G, Castellanos M, May ST, Lotto AA, Sacks H, Symonds $\mathrm{ME}$, Budge $\mathrm{H}$. Gene pathway development in human epicardial adipose tissue during early life. JCl Insight. 2016;1(13):e87460. 
112. Sacks HS, Fain JN, Bahouth SW, Ojha S, Frontini A, Budge H, Cinti S, Symonds ME. Adult epicardial fat exhibits beige features. J Clin Endocrinol Metab. 2013;98(9):E1448-55.

113. Shimizu I, Aprahamian T, Kikuchi R, Shimizu A, Papanicolaou KN, MacLauchlan S, Maruyama S, Walsh K. Vascular rarefaction mediates whitening of brown fat in obesity. J Clin Invest. 2014;124(5):2099-112.

114. Shimizu I, Walsh K. The Whitening of Brown Fat and Its Implications for Weight Management in Obesity. Curr Obes Rep. 2015;4(2):224-9.

115. Roberts-Toler C, O'Neill BT, Cypess AM. Diet-induced obesity causes insulin resistance in mouse brown adipose tissue. Obesity (Silver Spring). 2015;23(9):1765-70.

116. Chang L, Villacorta L, Li R, Hamblin M, Xu W, Dou C, Zhang J, Wu J, Zeng R, Chen YE. Loss of perivascular adipose tissue on peroxisome proliferator-activated receptor-gamma deletion in smooth muscle cells impairs intravascular thermoregulation and enhances atherosclerosis. Circulation. 2012;126(9):1067-78.

117. Buckley ML, Ramji DP. The influence of dysfunctional signaling and lipid homeostasis in mediating the inflammatory responses during atherosclerosis. Biochim Biophys Acta. 2015;1852(7):1498-510.

118. Carriere A, Jeanson $Y$, Berger-Muller $S$, Andre $M$, Chenouard V, Arnaud E, Barreau C, Walther R, Galinier A, Wdziekonski B, Villageois P, Louche K, Collas P, Moro C, Dani C, Villarroya F, Casteilla L. Browning of white adipose cells by intermediate metabolites: an adaptive mechanism to alleviate redox pressure. Diabetes. 2014;63(10):3253-65.

119. Dozio E, Vianello E, Briganti S, Fink B, Malavazos AE, Scognamiglio ET, Dogliotti G, Sigruener A, Schmitz G, Corsi Romanelli MM. Increased reactive oxygen species production in epicardial adipose tissues from coronary artery disease patients is associated with brown-to-white adipocyte transdifferentiation. Int J Cardiol. 2014;174(2):413-4.

120. Friederich-Persson M, Nguyen Dinh Cat A, Persson P, Montezano AC, Touyz RM. Brown Adipose Tissue Regulates Small Artery Function Through NADPH Oxidase 4-Derived Hydrogen Peroxide and Redox-Sensitive Protein Kinase G-1alpha. Arterioscler Thromb Vasc Biol. 2017;37(3):45565. 


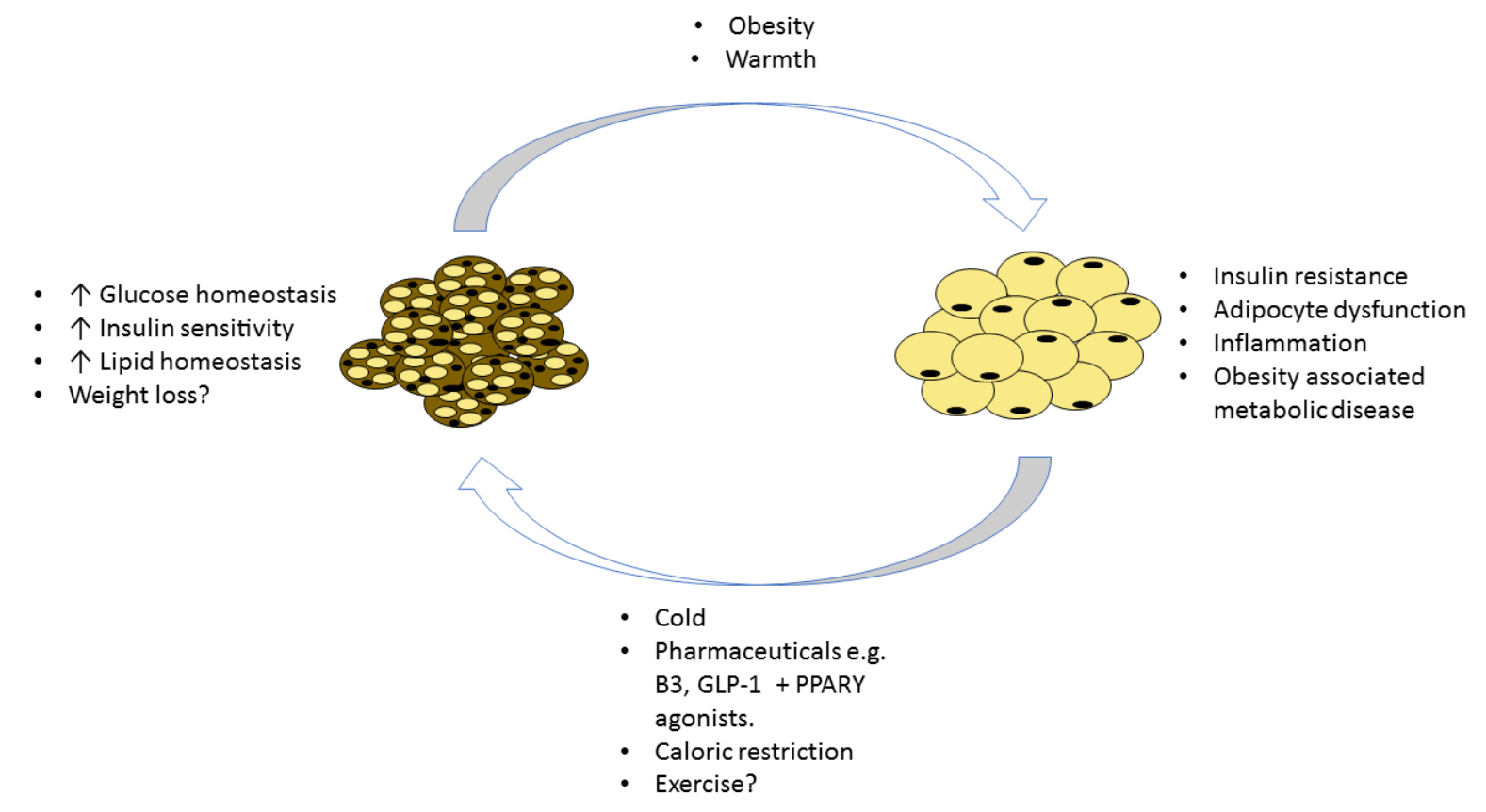

Figure 1. Overview of brown-to-white adipocyte transition, associated metabolic alterations and regulatory factors. 


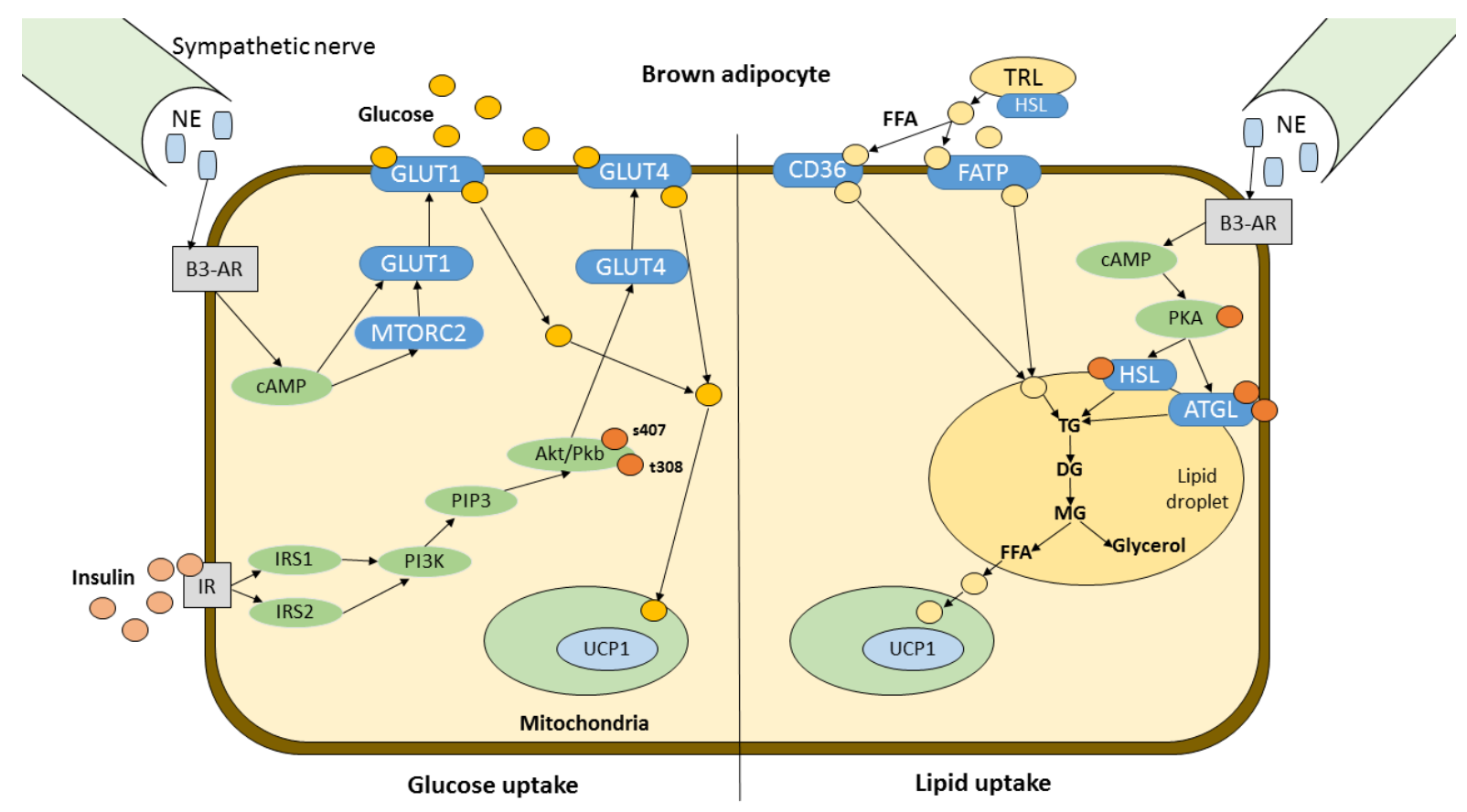

Figure 2. Overview of mechanisms regulating glucose and lipid metabolism in brown adipocytes. Discussed in detail in text. 